\title{
A comparative study on glocal commercial advertisement perceptions - British and French viewers' responses to Red Bull
}

\author{
Kerstin Bremser* \\ Department of International Business, \\ Faculty of Business and Law, \\ Pforzheim University, \\ Tiefenbronner Str. 65, D-75175, Pforzheim, Germany \\ Email: kerstin.bremser@hs-pforzheim.de \\ *Corresponding author \\ Nadine Walter \\ Department of International Marketing, \\ Faculty of Business and Law, \\ Pforzheim University, \\ Tiefenbronner Str. 65, D-75175, Pforzheim, Germany \\ Email: nadine.walter@hs-pforzheim.de

\section{Véronique Goehlich} \\ Department of International Business, \\ Faculty of Business and Law, \\ Pforzheim University, \\ Tiefenbronner Str. 65, D-75175, Pforzheim, Germany \\ Email: veronique.goehlich@hs-pforzheim.de
}

\begin{abstract}
This exploratory study analyses advertising viewers' perceptions using the same well-known person across different countries. Depending on their cultural background the interviewees associated very different feelings with the historical character shown in the cartoon. Additionally, the articulation and the style of the underlying music were perceived in different ways by both cultures. However, the results show that even though the commercial and the lyrics are differently understood and interpreted, the targeted marketing message is equally conveyed. The differences in perceptions observed are correlated with the Hofstede indexes for cross-cultural dimensions. This study is the first one to analyse perceptions about the same historical celebrity used in advertising among different countries and to correlate them with the Hofstede dimensions. It can thus give answers to the applicability of a certain type of advertising in different cultures, given that Hofstede dimensions are available for the selected countries.
\end{abstract}

Keywords: advertising; UK; France; standardisation; adaptation; Hofstede cultural dimensions. 
Reference to this paper should be made as follows: Bremser, K., Walter, N. and Goehlich, V. (2018) 'A comparative study on glocal commercial advertisement perceptions - British and French viewers' responses to Red Bull', Int. J. Comparative Management, Vol. 1, No. 4, pp.333-354.

Biographical notes: Kerstin Bremser is a Professor of International Business at Pforzheim University, Germany. She holds a Master's degree in European Management from the Otto-Friedrich University of Bamberg, Germany, and a $\mathrm{PhD}$ from the University of St. Gallen (HSG), Switzerland. She has been working for McKinsey \& Company and the internal management consultancy of Degussa AG in Frankfurt. She focuses in her teaching and research on strategic issues in the tourism industry and cultural difference between Europe and South America. She regularly serves as Guest Lecturer at various Spanish-speaking universities (Universidad del Pacifico in Lima, Peru and ESAN University, Lima, Peru).

Nadine Walter is a Professor of International Marketing at Pforzheim University, Germany. She holds a Master's degree in Business Administration from Mannheim University, Germany, a MBA from the University of Massachusetts at Dartmouth, USA, and a PhD from the University of Hamburg, Germany. She has worked for six years at McKinsey \& Company as a consultant. Her research interests are branding (esp. international branding and brand experience) and innovative marketing. She teaches in the executive education program at the St. Galler Management Institute in Switzerland and serves as Visiting Professor at Tias at Tilburg University (Netherlands).

Véronique Goehlich is a Professor of International Business at Pforzheim University, Germany. Her main teaching and research focus lie in intercultural management and in Franco-German economic relations. She is responsible in the Business School for cooperations with various French partner universities. She holds a Master's degree from Georgia Institute of Technology (USA) and a Doctoral degree in Material Engineering from the Université Technologique de Compiegne (France). She has many years of private sector experience working as marketing director and as a manager in international distribution companies in the materials and steel industry.

This paper is a revised and expanded version of a paper entitled 'Global commercial in local markets: best practice from Red Bull?' presented at Euromed Conference, Verona, Italy, 16-18 September 2015.

\section{Introduction}

In 1983, Levitt (1983) published his seminal article on globalisation of products. Since then scholars have debated about the question whether advertising needs to be locally adapted, whether it can be globally standardised or whether a glocal approach, i.e., a combination of both strategies is to be adapted. In a glocal approach some elements of advertising are standardised (e.g., copy strategy) and some others are adapted to local needs (e.g., language). More recent literature favours a glocal approach with some degree of adaptation to local tastes and culture (Light, 2013) and points out that cultural factors can influence differing brand acceptance (Mooij, 2010).

One way of achieving brand acceptance in different cultures is via celebrity endorsement, where the celebrity is intentionally selected to represent certain cultural 
features (McCracken, 1989). In this sense, a celebrity is defined as: "any individual who enjoys public recognition and who uses this recognition on behalf of a consumer good by appearing with it in an advertisement" [McCracken, (1989), p.310].

Red Bull, the energy drink from Austria, is distinguished by a global standardised marketing strategy addressing young, energetic people loving to have fun (N.N., 2012). Apart from event marketing, Red Bull also uses traditional advertising, especially television commercials. Red Bull is known for its cartoon-like ads which centre on the message that 'Red Bull creates wings'. They are standardised because the only adapted issue is the language as well as the countries the commercials are shown in. This article focuses on a television ad published in 2012 which tells the story of French emperor Napoleon in a condensed version. It has been screened in France and Britain in 2012 (as well as in, i.e., Italy, Sweden and South Korea among others). This exploratory study is a pre-test of a larger survey intended for all European markets the commercial has been screened in. It investigates if the Red Bull is interpreted differently among the UK and French citizens and if Napoleon actually conveys the brand's meaning. It also intends to verify, whether the observed findings correlate with the Hofstede dimensions. The UK and France have been chosen due to the fact that both countries differ considerably within Europe with regard to culture, humour and acceptance of conventions. Referring to the scales developed by Hofstede and Minkov (2010) and Hofstede (2001), those two countries represent the largest cultural differences among the countries the commercial was screened in. Also, these two countries share a very long history of alliances, wars and rivalries. The historical ties between the two countries are complex and celebrities such as Napoleon are very famous but have a controversial esteem.

The remainder of the article is structured as follows. The next section presents in seven subsections a literature review introducing the standardisation/localisation debate in Marketing, the six dimension model of Hofstede as well Celebrity Endorsement theories. Afterwards, the employed methodology is introduced. Finally, results are discussed in six subsections structured according to the nationality of the interviewees and closing in on comparative views. At the end, conclusions are drawn with a special focus on marketing professionals.

\section{Literature review}

This research is based upon three areas of marketing literature: Firstly, the research on standardised vs. localised advertising, secondly on the Hofstede model, and thirdly on the use of celebrities in commercials.

\subsection{The origins of the standardisation/localisation debate in marketing}

The academic discussion regarding standardisation and localisation in marketing has its origin in the field of advertising: Elinder (1965) was the first to bring up the question, how far international advertising can be standardised in his outstanding article 'How international can European advertising be?' He points out that increasing similarities among European consumers make uniform ads feasible. However, a truly intense debate only started in the 1980s with Levitt's (1983) article 'The globalisation of markets'. Levitt develops Elinder's early theories on the homogeneity of markets and argues that 
the homogeneity of markets evolves steadily. Various authors have criticized his views in the following years arguing that his conclusions are too radical. For instance, Boddewyn et al. (1986) call his views 'visions' and see national differences in consumer tastes and habits as the major obstacles to a standardisation. Further to this discussion, more research has been conducted to identify similarities or differences of markets and cultures in order to evaluate the prerequisites and the potential for standardisation (Baabbaki and Malhotra, 1995; Zou and Cavusgil, 2002).

\subsection{The debate on global, local and glocal advertising}

After Elinder's (1965) widly discussed article, further research related to the field of advertising centres regarding the question whether advertising is culture-bound (emic) and therefore a local adaptation is needed, or if it is culture-free (etic) and a global standardisation approach can be applied - or a mixture of both strategies (glocal) is needed, where some elements of advertising are standardised and some others are adapted to local needs. Firstly, global standardised advertising is regarded as most efficient and with the highest level of message consistency. Empirical research finds it to be used largely in practice (Domzal and Kernan, 1994; Duncan and Ramaprasad, 1995; Torres Moraga and Muñoz Navarro, 2006). Secondly, local adaptation is seen by a large group of authors as necessary to comply with cultural differences. Kanso (1992), Whitelock and Rey (1998), Oosthuizen (2004), Javalgi et al. (1995) and Gau (2007) analyse various elements of advertising and all conclude that local adaptation is the most used form. Thirdly, another group of authors argue that a glocal approach, i.e., a combination of both, is needed (among others Zandpour et al., 1994; Jiang and Wei, 2012). This means that predominantly a global advertising strategy is followed, but local adaption is used in certain circumstances, e.g., the adaptation of images or language for certain culturally diverse countries. Authors from all three schools of thought agree that the level of cultural similarity is to be the most important driver to determine whether a global, local or glocal approach is most suitable.

\subsection{Culture-bound advertising}

Wadia (1965), a cultural anthropologist, was one of the first authors to highlight the importance of culture to marketers and advises them to distinguish global (universal) traits, which can be used all over the world, and local (cultural) specific traits and tastes, where marketing has to be adapted. Cultural-bound means that it is valid only within a particular culture, whereas cultural-free means that it is not limited to one or several cultures only. Wadia (1965) concludes that marketing in general is culture-bound and will be meaningless if not adapted to local needs. This is confirmed in other early works by Buzzell (1968) and Ricks et al. (1974) who contend that differences in national culture and local market conditions call for local adaptation of marketing. Kanso (1992) researches advertising strategies of Fortune 500 companies and finds that most advertising is localised. And these high levels of adaption are not only the case for culturally rather dissimilar countries (see Lin, 1993; Javalgi et al., 1995 for Japan and the US), but even for countries within Europe: Whitelock and Rey (1998) analyse over 600 television commercials in France and in the UK and come to the conclusion that "these 
two countries appear to be too culturally dissimilar to allow much scope for standardised advertising". Various other authors prove that standardisation pursued for rather inhomogeneous customer segments is prone to failure: Oosthuizen (2004) points out those standardised marketing messages are generally termed in a way to find the lowest common denominator across cultures; hence, many messages get lost because of different (cultural) perspectives of the receivers. Chan et al. (2007) find different dimensions of print advertising perceptions in China and Germany and come to the conclusion that such perceptions had a significant impact on consumers' rejections of the product or the brand.

\subsection{Culture-free advertising}

After Levitt's (1983) article researchers started to investigate the usefulness of truly global and standardised advertising. The three widely mentioned advantages are cost savings (e.g., less complexity in the creative design of only one standardised communication concept and less staff due to the centralisation of marketing communication teams), increase in brand value due to a global consistent image and better negotiation position vis-à-vis powerful international retailers (Craig and Douglas, 2000; Quelch, 1999; Theodosiou and Katsikeas, 2001; Duncan and Ramaprasad, 1995). Besides the analysis of the advantages of a standardised approach, researchers focused their efforts largely on the question which central elements of an ad campaign are being standardised and are therefore considered to be culture-free. This can be visual components, verbal elements or other parts: Domzal and Kernan (1994) analyse identical ads shown in several countries and discern creative features that are globally understood. The sample covers different product categories. Ads featuring the brand in a visual and concrete way using real portrayals (e.g., logo or product) are more likely to be understood across cultures. Use of excessive words and metaphors should be avoided. In their research they detected a higher usage of culture-free than culture-bound ads. Solberg (2002) conducts a survey among Norwegian multi-national companies and finds that a globalised advertising approach is most widely used. Torres Moraga and Muñoz Navarro (2006) distinguish between three different types of cultures used in commercials: global, local and foreign (i.e., associating a product with a specific foreign country, in order to benefit from its culture; examples are Switzerland for watches, Germany for cars). They conclude that the global approach is most commonly used and most promising regardless of product category. More recent research emphasises the meanings associated with culture-free advertising: since historically products (especially luxury products) are known for their country of origin, culture-free advertising focusing on the country of origin will convince consumers more (Strebinger et al., 2018).

\subsection{Glocal approach}

Whilst a large part of the research discusses whether a global approach (culture-free advertising) or a local approach (culture-bond advertising) is suitable, various researchers suggest that a mixture of both is appropriate - taking into account that countries are never fully heterogeneous or homogeneous. In this case, typical local elements as, i.e., Chinese characters are included in the advertisement (He and Wang 2017). Research concludes that the level of globalisation and/or localisation depends on certain factors such as: 


\subsubsection{Geographical areas with cultural similar/dissimilar countries}

The vast majority of researchers agree that the level of globalisation or localisation of advertising depends on how culturally similar or dissimilar countries are. The homogeneity or heterogeneity of cultures are explained predominantly by using Hofstede's typology (Hofstede, 1980) - which is used by Zandpour et al. (1994), Albers-Miller and Gelb (1996) and Okazaki and Rivas (2002) - or Hall's (1976) high- and low-context typology - which is used by Biswas et al. (1992), Taylor et al. (1997) and Cho et al. (1999).

Since cultural heterogeneity demands a likely complex and costly adaptation of advertising, the focus of research lies mainly on the comparison of culturally different regions, such as South America and the West [e.g., Falk et al. (1999) for Mexico and the US and Zandpour et al. (1994) for Mexico, Argentina and Brazil compared to 20 other European, Arab and Asian countries] and to an even larger extent Asia and the West. This includes Japan and the USA (Lin, 1993; Javalgi et al., 1995), Korea and the USA (Cho et al., 1999; Taylor et al., 1997) and China and the West (Ji and McNeil, 2001; Chan et al., 2007) as well as emerging economies (China, India) and developed countries (Nicholson and Khan, 2017).

Besides the comparison of South America or Asia and the West, a second research field also focuses on (rather dissimilar) Western countries, such as the USA versus European countries. For example, Jiang and Wei (2012) discover that the USA multinationals are very often adopting glocal strategies in advertising, whereas European companies are more akin to adopt a global strategy. Biswas et al. (1992) identify dissimilarities between the USA and French advertising campaigns in terms of the degree of emotional appeal, the level of formativeness, and the use of sex appeal and humour. However, also similarities can be found: Wiles et al. (1995) find similar gender roles in advertising in Sweden, the Netherlands and the USA.

Subsequently, research on regions with rather culturally similar countries is rare. It focuses mainly on countries in Latin America or on Arab countries. Karande et al. (2006) discover in an empirical study analysing the (culturally relatively similar) Arab countries of Egypt, Lebanon, and the United Arab Emirates, that for culturally normative ad content (such as the depiction of women consistent with societal norms) standardisation is appropriate even if the countries have socio-economical differences. Research of countries within Europe hardly exists. This research gap shall be closed with this study which focuses on the UK and France.

\subsubsection{Product- or category related reasons}

The majority of researchers agree that marketing is easier to standardise for industrial products than for consumer goods, since the latter are rather based on not-so-easy to change local habits and tastes (Boddewyn et al., 1986). Within consumer goods, there are differences between product categories. The potential for global advertising is higher for product categories "that have come to symbolise modernity and cosmopolitanism rather than tradition" (Alden et al., 1999). Alden et al. (1999) prove empirically that the level of standardisation in television advertising is lowest for food and highest for durable high-tech products - with household/personal care and low-tech durable products in-between. This is consistent with the longstanding believe that food is a rather local 
category. Cervellon and Dubé (2000) come to the conclusion that food ads can only be standardised to a certain degree given local tastes. In a sample of French and English Canadians, despite their same nationality, food ads directed at the French speaking population emphasise pleasure whereas those directed at English speaking customer prioritise health aspects. However, more recent studies, also confirm an increasing standardisation within food advertising. Czarnecka et al. (2013) find that within the European Union food ads tend not to be based on local cultures anymore.

Interestingly, none of the above-mentioned studies focus specifically on beverage advertising, but only analyse the food category as a whole. Cervellon and Dubé (2000) for example include beverages, snacks, cereals, condiments/ingredients, frozen/convenience food, and others. However, we believe that beverages are less affected by local tastes as globally standardised products in alcoholic beverages - such as beer (Heineken), wine (Robert Mondavi) and spirits (Smirnoff) - and correspondingly non-alcoholic beverages - such as carbonated drinks (Coke), water (Evian) or coffee (Starbuck's) - show. We attempt to close that research gap by focusing on a beverage product- the Red Bull energy drink.

\subsubsection{Components of an advertising campaign}

Already over 25 years ago, Sandler and Shani (1992) stated that "the standardisation question has seemingly moved from an all-or-nothing issue to one of the degree of standardisation of the various advertising elements". Early research found evidence of pattern standardisation, where the same creative theme is used in most markets, adapting other executional elements if necessary (Sorensen and Wiechmann, 1975; Dunn, 1976; Colvin et al., 1980). However, so far there is only little agreement with regard to which specific elements in an advertising campaign are commonly standardised or adapted. Domzal and Kernan (1994) find that the sole standardisation of visual elements (not the copy) has a higher likelihood of success since it appeals to culturally diverse target audiences. Zandpour et al. (1994) develop a model to predict which parts of ads must be adapted. They distinguish between creative strategy, informativeness and style, and offer a guide how these elements need to be adapted with regard to the cultural dimensions developed by Hofstede. Whitelock and Rey (1998) observe that (between France and the UK) scenic background and characters were the most commonly standardised elements in television ads in contrast to the text and slogan. They believe that this is due to the fact, that text and slogan can be easily and cost effectively (e.g., via voice-over) adapted to local expectations.

As demonstrated above, the majority of researchers advocate an advertising strategy that takes local culture into account. A glocal approach - where key elements of an advertising ad are standardised (mainly the advertising message, culture-free visuals), and only a few essential adaptations are made (language, visuals with culture-related meanings) - is considered to be the best compromise. The authors fully support this view, since it allows for cost savings and a globally consistent image - and at the same time avoids customers' rejection, since it takes cultural particularities into account. This approach is also followed by Red Bull's 'gives you wings' advertising campaign which uses identical ads in all countries - but translates text and sometimes makes slight verbal/visual changes. 


\subsection{Introduction of the Hofstede model}

The ad analysed in this article is the Napoleon Cartoon Ad which was aired both, in the UK and in France, with only slight adaptations (language, accent, some wording). However, we believe based on the research above, that Western markets, including the UK and France, are culturally still dissimilar. Both countries are located on the opposite sides of scales for high/low context, power distance, masculinity, indulgence as well as uncertainty avoidance. The authors consider these differences as the major reason why companies still adapt their advertising campaigns to a certain degree, as results of Biswas et al. (1992) and Whitelock and Rey (1998) show. Therefore, our research proposition is that French and British viewers perceive and interpret the ads differently. Our further aim was to reflect on the Hofstede dimensions and to correlate these with the findings of our study.

The six cultural dimensions from the Hofstede model as listed in Table 1 represent independent preferences for one state of affairs over another, distinguishing countries (rather than individuals) from each other. Four of his dimensions derived from his research conducted at IBM subsidiaries in 76 countries, after questioning approximately 116,000 employees between the years 1967 to 1973 (Hofstede, 1980). These are power distance, individualism vs. collectivism, masculinity vs. femininity and uncertainty avoidance. 14 years later, the fifth dimension long term orientation vs. short term orientation was added to the dimensional model (Hofstede, 2001) Finally, in 2010 the dimensional model was completed with the addition of indulgence vs. restraint. There are many objections against Hofstede dimensions. The most popular one is that the ethnic units which are part of a domestic population are neglected and that a homogeneous whole for the all national group is assumed. Moreover, Hofstede study was based on a one company approach (all data have been collected inside of IBM) and might be by now outdated. However, his huge study has been very relevant in the eighties and still gives today multi-national practitioners good guidance into the global environment (Jones and Hofstede, 2007). Although country scores on the dimensions are relative and might be questioned, the comparison of cultures on the basis of Hofstede findings can give a helpful orientation. In Table 1, the score for France and the UK are summarised.

Table 1 Scores for Hofstede dimensions for France and the UK

\begin{tabular}{lcccccc}
\hline Indexes & $\begin{array}{c}\text { Power } \\
\text { distance }\end{array}$ & Individuality & $\begin{array}{c}\text { Uncertainty } \\
\text { avoidance }\end{array}$ & Masculinity & $\begin{array}{c}\text { Long term } \\
\text { orientation }\end{array}$ & Indulgence \\
\hline $\begin{array}{l}\text { France } \\
\text { United }\end{array}$ & 68 & 71 & 86 & 43 & 63 & 48 \\
$\begin{array}{l}\text { Kingdom } \\
\text { Difference }\end{array}$ & 35 & 89 & 51 & 66 & 51 & 69 \\
$\begin{array}{l}\text { between } \\
\text { the UK } \\
\begin{array}{l}\text { and } \\
\text { France }\end{array}\end{array}$ & 18 & 46 & 23 & 12 & 21 \\
\hline
\end{tabular}

Source: Hofstede (2001) 


\subsection{The use of celebrities in advertising}

Celebrity endorsement has evolved throughout history and dates back to the 18th century where queens or kings awarded a 'royal warrant' to their suppliers that could be used for marketing or even appeared on packaging of the product (Erdogan, 1999; Heald, 2001). Scott (1991) goes back even further and dates celebrity endorsement to the ancient Roman and Greek societies where goods were associated with certain gods or decorated with scenes from the lives of well-known heroes. She spans the line to the medieval times where gods did no longer appear on goods (since they could not be personified) but instead Christian saints. Napoleon as well as his wife Joséphine were frequently pictured on items during their life-time. With the advent of print media, celebrity endorsement became more visible and increasingly popular. Nanda and Khandelwal (2017) give a detailed overview of the development of the literature on celebrity endorsement since after the second world war and detect a gap in literature concerning cross-cultural studies.

Within research, literature centring on celebrity endorsement includes not only real characters as athletes or actors but also cartoon characters. These are often associated with advertisement directed towards children and show effectiveness there (Boyland et al., 2012; Hebden et al., 2011; Ogilvy and Raphaelson, 1982). However, not only food items are adorned with cartoon characters, also airlines - air nippon painting Pokemón scenes on their planes whereas EVA Air adorned them with Hello Kitty images - use this technique in order to increase visibility (Wang and Ngamsiriudom, 2015).

The usefulness of a celebrity in advertising is on the one hand explained through the source credibility model (Hovland et al., 1953). It briefly states that people evoking trustworthiness and expertness are credible and therefore persuasive. On the other hand, the source attractiveness model developed by McGuire (1985) states that attractive physical features or admired lifestyles create a positive attitude towards the product which could translate in purchases. Furthermore, McCracken (1989) centres on the meaning transfer. Meaning is transferred from the endorser to the customer. Therefore, there should be congruence between the product and the endorser (i.e., athletes endorsing protein bars, healthy drinks, beauty products).

According to Hofstede, "culture is defined as collective programming of the mind that distinguishes the members of one group or category of people from another" (Hofstede, 2001). The influence of heroes (role models) is thereby significant. Also learning values and understanding symbols (myths, legends, dress, jargon, gestures, etc.) is part of the socialisation process through mainly family, school, religion, friends, media, work place and many other sources (Jones and Hofstede, 2007). The use of celebrities in advertising is considered to be effective since consumers are more likely to favour products endorsed by celebrities. It is a widely used technique that has to be carefully applied as Prentice and Zhang (2017) showed for China. Key characteristics for a successful celebrity are attractiveness, trustworthiness, expertise, level of involvement, number of endorsements and audience characteristics as well as a match between the brand and the celebrity (Edson Escalas and Bettman 2015). The use of celebrities in advertising generally implies a cultural-bound strategy, as various studies prove. Cross-cultural studies of celebrity endorsement are rare. Mostly, countries with opposing values in cultural dimensions (i.e., collectivist vs. individualistic, high context vs. 
low-text, etc.) are observed. Biswas et al. (2009) undertake a cross-cultural study in India and the USA to detect if celebrity endorsement has an equal appeal to citizens of both countries. They find that Indian consumers are more likely to be affected by celebrity endorsement because of the celebrity's perceived status and glamour, and Americans rather by the celebrity's expertise and achievements. Um (2013) analyses the celebrity endorsement in Korea (a rather collectivistic culture with a high-context communication style) and the USA (a rather individualistic culture with a low-context communication style). Compared to the US, in Korea celebrity endorsement is more widely used, because being from a collectivist country Koreans trust recommendations more than fact-based information. In a study from Chao et al. (2005) the authors detect that certain congruity must exist between the celebrity and the product endorsed. Here, Austrians prefer German presenters to American celebrities in ads regarding high-tech products because Germany is strongly associated with high-technology, quality, and reliability, whereas America is not (as much). Marimoto and Chang (2009) come to a similar conclusion regarding fashion ads in Japan. Fashion ads more often show Caucasian than Asian models since they are associated with higher status or luxury.

These examples show that the usage of celebrity endorsement varies largely between countries due to the different perceptions of customers, based on the different cultural background of the viewer. Agarwal et al. (2010) suggest that these cultural backgrounds are converging and therefore culturally similar market segments appear in different countries. This implies that it would be possible to use the same celebrity endorsing an identical product in different countries. Many companies use this strategy across different countries (i.e., Tiger Woods for Rolex watches, David Beckham for Breitling watches, David Bluman for Hermès, Michael Jackson for PepsiCo...). Many of these companies serve a global set of customers (luxury products) or the globally converging segment of young, energetic people. However, to our knowledge, no empirical research exists yet that analyses the usage of the same celebrity or historical figure across different nations. Moreover, no empirical research tries to relate perception findings with the wellestablished Hofstede dimensions. This research wants to close the gap, and analyses ad viewers' understanding of the ad using the same well-known figure across different countries. As a result, we expect that due to the above mentioned differences in local celebrity endorsement, the understanding of the same person across countries will also differ. Thus, we have included three sub questions in our research:

- Does a historical character and its (potentially) dissimilar perception in different countries influence a brand's meaning?

- Does a historical character succeed in conveying the core meaning of the brand in different countries?

- Will the Hofstede dimensions be of any help for assessing in advance whether an historical character will be positively perceived?

\section{Methodology}

The aim of this study is to assess the cognitive and emotional response to an ad in an international context. Several methods exist that measure ex-post advertising effectiveness (De Pelsmacker et al., 2017). Two types are commonly used: Firstly, 
penetration tests that primarily measure recall and recognition. Secondly, progress or sales-effect tests that measure buying intention (intended-to-buy tests; inquiry/coupon response), actual purchases (sales results test) or attitude. For this study an attitude test with qualitative research seems most suitable. The research question is still of explorative nature and aims to reveal the ideas and believes of the viewers. Quantitative research would be not appropriate since the critical issues are not understood well enough to phrase general hypotheses. Qualitative attitude tests can be conducted over in-depth-interviews, focus groups or projective ideas. Since we measure individual attitude, in-depth interviews seem most suitable.

In order to research the global understanding of culture-free ads, a particular Red Bull commercial was chosen. This commercial is special in two ways: on the one hand, it figures a national celebrity and stands for certain aspects of French history that people from other nations might not understand. On the other hand, apart from France the ad was screened in several other countries, including the UK, where Napoleon also historically is an important person. In general, Red Bull standardises commercials, often using no words at all except for the marketing slogan 'Red Bull gives you wings' which is translated into the local language. Sometimes a song is added to the cartoon with lyrics describing the action in the movie. Red Bull Country organisations can choose from a series of commercials and decide which ones are apt for their countries. Decision depends on level of familiarity with the issue and market development among others. For this paper, we performed a pre-test as starter for a larger survey which will then be mainly quantitative. In this first exploratory step a qualitative method approach was used consisting of semi-structured in-depth interviews within preselected groups. In March and April 2015, a sample of ten respondents (five French and five British) took part in the first round of interviews, a sample of the interview guidelines are found in the Table A1. The common characteristics for this first sample were to have the same nationality, to live in the one country under scrutiny and to know the brand Red Bull. The ages of the respondents varied between 20 and 55 years old. Purposeful sampling was used in order to select persons that could provide significant and relevant information. The participants were contacted either through professional social networks such as Xing and LinkedIn or through personal contacts within French and British companies. The results for this first sample differed significantly depending on the age and on the professional status of the respondent. Therefore, it was decided to conduct a second round of interviews between January and March 2016 with a group of 22 respondents (11 French and 11 British) with all same age (19-21 years) and same professional status (all students in the field of Economics), the two others criteria (nationality and location of residence) remaining unchanged. We assumed that this new sample would be more homogeneous regarding potential exposure to the Red Bull brand. After informing the interviewees about the topic via e-mail and sending them the link to the clip, the interviews were scheduled and carried out face-to-face, if possible, or via phone and lasted for 30 minutes. The interviewees were shown the Red Bull cartoon with lyrics from a famous French rapper, this was done twice in order to understand the wording correctly. Then the respondents were asked about the main and secondary message of the commercial as well as their understanding of Napoleon and interpretation of it. For a better understanding, the lyrics of the cartoon are transcribed below: 


\begin{abstract}
"Now he was just a boy from Corsica. A math student with a decent score-sica. Then he helped the entire big guys storm the Bastille, which made some people think he was the real deal. From Austria to Egypt and Italy, if you wanted something done he was the man to see". I am the French emperor "he liked to say, the ones who disagreed well they didn't get to stay. Outnumbered by his enemies he found himself banished, to a place called Elba where he basically vanished. He managed to escape "because he knew a few things, like for instance Red Bull gives you wings." (Own transcript)
\end{abstract}

Comparing the French and English commercial, it has to be stated that they are not exactly alike. Although the pictures are identical, the lyrics in French and English are similar but no exact translations, in order to keep the rhymes. In English, the word 'score-sica' does not exist, it has been invented to rhyme better with 'Corsica'. In addition, the French ad is performed by a famous rapper (Kaaris) with a strong accent showing his immigrant (from Ivory Coast) origins. The English song is also a rap, but with a standard British accent and no particular, well-known performer.

The independent variables of this research are therefore nationality, age and professional status while the dependent variable is perceived messages in the cartoon. In order to validate the data, the findings were sent to four research participants in order to obtain feedback and correction. They confirmed that the correct interpretation was reached. Also, all answers have been reported on the questionnaires which have been filed away (Elliott and Timulak, 2005). After collecting the data, they were divided into distinctive meaning units (Rennie et al., 1988) like symbols associated with Napoleon, main messages and second messages associated with the cartoon, typical keywords associated to Red Bull and assessments whether this cartoon can be efficiently used in France and the UK.

Finally, these meaning units were related to broader domains (Hussy et al., 2013) like culture, identification to the cartoon through historical background and perception of critics toward the society. These domains provided a conceptual framework for the data, and addressed the research questions stipulated before.

\title{
4 Discussion of results
}

The following section is structured along the different research propositions and nationalities of the respondents.

\subsection{Research proposition 1: influence on brand's meaning - French respondents}

Looking at the research proposition (Does a historical character and its (potentially) dissimilar perception in different countries influence a brand's meaning?) the interviewed French people indeed had a deep understanding of Napoleon.

The ad shows characteristics of Napoleon (position of his hand, shape of his hat, dress code, facial expressions, people around him, places where he is pictured) that are strong symbols associated with Napoleon and taught accordingly in France. Most French respondents systematically noticed the position of his hand, as well as the places pictured. These places form an important part of French history since Napoleon conquered large parts of Europe but lost also battles against the British army for instance in Egypt. 
Overall, the French people recognised the following symbols since they convey certain specific meanings that are listed below:

- The positioning of the hand is a symbol of good manners during the times that Napoleon lived in. It was not seen as being educated to have your arms hanging down. Since his clothes had no pocket he always stuck one hand in his coat (La Salle, 1788).

- The shape of his hat was the typical French military hat during revolutionary times. Thus he illustrates his closeness to the ideals of the French revolution (Scully, 2011)

- His dress code is also a very typical military outfit of the times. Napoleon was very close to the military, entered military school at the age of ten and was always fond of the military. He is well known for his great strategies and his good command of the army (Asprey, 2000).

- The people around him all symbolise parts of his life or his career. His first wife Joséphine, who herself lost her first husband during the French Revolution, is pictured as well as noble people dying on the guillotine. Even though Napoleon was from a noble family, he proclaimed his beliefs in a meritocratic society where everything was through hard work instead of birthright achievable. He himself did not live this ideal since he promoted his entire family to power once he had proclaimed himself emperor (Lyons, 1994).

- The places where he is pictured conform to the phases of his life. He won battles in Egypt and Italy and was exiled to the Island of Elba from which he escaped, however, died little later without family and support on the island of St. Helène (Prévot, 2011).

The French respondents were able to recognise many of these symbols and places and interpret them correctly.

\subsection{Research proposition 1: influence on brand's meaning - British respondents}

The symbols associated with Napoleon are not familiar for non-French people. Only the most famous ones (dress code, position of the hand) are depicted in movies/paintings and therefore better know. The British therefore did not recognise many of the symbolism depicted in the commercial. Additionally, British people are not familiar with many different episodes of the Napoleonian wars (i.e., battles in Egypt) since the battle of Trafalgar in Spain has been the clearest and quickest victory of the British army against Napoleon troops. British respondents focused on the items that Napoleon was known for (dress code, hand). Moreover, in total, the British noticed lesser items than the French, given the numbers in the columns 'never' and 'once' observed.

\subsection{Research proposition 2: historical character - French respondents}

To answer the second research proposition (Does a historical character succeed in conveying the core meaning of the brand in different countries?) we looked at the perceptions evoked through the Red Bull commercial. The French group differed in their 
feelings towards the Ad. Even though at first glance most commented that it was funny, after a moment they added other feelings, as for instance "it is shocking since the guillotine is nothing humorous", "original because Napoleon is well known but died without power and recognition". Additionally, it was asked if Napoleon is conveying the meaning of the brand, i.e., gives you wings. Asked, if the commercial gave them wings, all respondents except one French person answered 'no'.

According to literature, the brand Red Bull can be characterised by the following adjectives: 'energetic', 'adventure loving', 'recreative', 'levity', 'youthful', 'brave/daredevil', 'cool', 'innovative', 'nothing can stop you', 'the world has no limits' (N.N., 2012). The respondents indicated that they could visualise all these aspects in the cartoon. Napoleon on the other hand is remembered for 'meritocracy', 'structure', 'order', 'military', 'war', 'despotism' (Bradley, 1975). In this case the historic truth of Napoleon contradicts the meaning of Red Bull. The French had a differentiated viewpoint ('famous leader', 'historic facts are wrongly displayed (Elba vs. St. Helena)', 'Guillotine is shocking, not funny', 'why Egypt?'). This is conforming to the statements of Scott (1991) who states that the celebrity always has to be seen in the historic context. The context conveys information about the character and what the celebrity stands for. For the French interviewees, the cartoon symbolises a critique to the existing meritocratic French system. Napoleon in their point of view stands for meritocracy, structure, mathematics, military and lack of tolerance (Gross et al., 2003), whereas the rapper who sings, Kaaris, is the exact opposite standing for opposing the rules and denying meritocracy. Kaaris has an immigrant background and grew up in Sevran, a very poor suburb of Paris. He stands for the hopeless youth of the poor suburbs. Thus, according to the comments made by the French interviewees, the juxtaposition of contemporary rap music performed by an assimilated French person with a cartoon featuring establishment and structured life of Napoleon even brings the French interviewee to get the message 'everything is possible (with Red Bull)'.

\subsection{Research proposition 2: historical character-British respondents}

When asked about their feelings, the British answered almost unanimously that the cartoon was 'funny' or 'entertaining' without interpreting other feelings into the ad. With regard to the fact of 'giving you wings', the central Red Bull slogan, all except for one Brit answered 'no'. Instead, the respondents were able to visualise all adjectives associated with Red Bull. Contrasting this to what Napoleon historically stands for, these facts were barely known by the British interviewees. For them Napoleon stands for "a small guy who achieved great things", "great French dictator who couldn't beat the British", "the French equivalent to Churchill". They did not associate meritocracy, only military and strategy with Napoleon.

\subsection{Research proposition 3: Hofstede scales}

For the third research proposition, it was asked whether the findings are correlating with the Hofstede dimensions (Table 1).

The power distance index has to do with the degree to which unequal distribution of power and wealth is tolerated. According to Hofstede, this index is much higher for French than for British people. Several symbols associated with superior social status and high power are depicted in the clip (body language and manors of Napoleon, codes 
associated to his rank, his uniform) and emphasise this aspect of the French society. These might not be so clear to the British people.

Regarding individuality both societies rank high on this scale, which fits well with the content of the clip. Napoleon is depicted as a loner.

Also, according to the higher uncertainty avoidance index of the French compared to the British people, French score very high and should be less willing on taking risks and more searching for stable, safe environments. Napoleon is shown self-assured, almost arrogant because he knows that nothing can harm him as his secret weapon, the Red Bull Energy drink, has been hidden under his waistcoat since childhood. Thus, he expresses a strong uncertainty avoidance with a pragmatic, laid-back superiority.

Looking at the Hofstede indulgence scale, French are supposed to behave more restrained in the working environment (indulgence index is lower for France than for the UK). These aspects are pictured in the clip through the strict Cartesian education given to Napoleon and his spirit for commitments, career and competition. The expected more indulgent attitude of the British should make them open for taking with humour the unexpected conclusion of the clip, showing Napoleon saving himself thanks to Red Bull.

At last, the index masculinity depicts the degree to which masculine traits like authority, assertiveness, performance and success are preferred to female characteristics like personal relationship, quality of life, harmony, etc. (Jones and Hofstede, 2007). According to the assessment of Hofstede, the French society should be more feminine than the British one, meaning that the French people would not typically support masculine heroes (Table 1). However, the clip depicts a very famous French masculine character, in constant search of power and success for himself. So the choice of celebrity does not seem to be adequate for French people according to Hofstede model. The British, who are higher on masculinity and individualism should be more sensitive to individual achievement, heroism, assertiveness, and material rewards for success, which are pictured in the clip through the actions and standing of Napoleon.

\subsection{Comparative views}

With regard to the first research proposition, French respondents did indeed show a deeper understanding than the British interviewees. It can be assumed that recollecting the specifics of the ad more precisely, shows a more intensive processing of the content and therefore a longer dealing with the ad, which in turn might improve the effectiveness of the glocalised TV-commercial.

Asked for the main message of the cartoon, the French and British respondents agree that 'Red Bull gives you wings' or 'Red Bull gives you the ability to do the impossible' (seven answers for each nation). Additionally, the responses of six French and five Brits centre on the idea of success and escape. Here, both groups show similar interpretations.

It is to be concluded that the main message, which is central to Red Bull, is perceived identical in France and the UK, and is therefore culture-free. However, since the French see more meanings in the ad than the British people, we consider the advertising in total to be not completely culture-free. French respondents commented on the secondary meaning associated with the cartoon, like. 'it shows the glory of France' or Napoleon shows the 'French method'. British respondents did not recognise a second meaning (five respondents answered 'not that I noticed' and two respondents were 'unsure'). The ad follows a glocal approach as suggested by Duncan and Ramaprasad (1995). This finding 
confirms the viewpoint of Czarnecka et al. (2013) that at least within the European Union advertising is not adapted to local cultures anymore and contradicts Cervellon and Dubé (2000) who found in their sample of Canadian customers that food ads were indeed adapted to the different tastes of Anglophone and Francophone Canadians. Despite different perceptions of the cartoon, both groups arrive at identical understandings of the brand's meaning.

The second research proposition dealt with Napoleon being able to convey the meaning of the brand. Here, feelings differ between both groups. In any case, positive feelings were mostly cited but French answers show a broader spectrum and are more diverse. British responses centred on being funny or amusing. Still, both groups 'get the message'. Concluding, on the conformity of this clip for use in France and the UK, one can say that the content seems to match well with the Hofstede dimensions, except for the fact that the clip depicts a masculine hero which, according to Hofstede, should not match with the French expectation for heroes.

Now analysing the open answers of the French respondents, they actually partially criticised the content of the clip, saying that the choice of Napoleon was not appropriate because he did 'a lot of harm to other countries and was only striking for power for his own family' (own data) Also the use of guillotine as a symbol for change and new era was found rather shocking and not funny. The French viewers were also annoyed though the clip showing traditional and military sides of his character combined with the rap music. The British described the clip as funny and perceived it entertaining, especially when combined with rap music.

With regard to the Hofstede dimensions, one can say that the historical figure of Napoleon and the humoristic combination of rap music with the clip gave the opportunity for both British and French respondents to assess and interpret the clip positively, however due to the different features in accordance with the Hofstede dimensions. The French reacted positively because of the elements supporting high power, high uncertainty avoidance and restrain. The British reacted positively because of the elements supporting high individuality, high masculinity and indulgence. The predictions based on the analysis of the content with the six-dimensions model from Hofstede fit well with the results of our empirical study. The respondents confirm that they noticed different aspects of the clip and of the music which impacted their impression in different manners. However the size of our segment is too small to draw further conclusions. On the basis of this first exploratory approach, it can be formulated as a research thesis that the use of the Hofstede dimensions for the local culture under scrutiny might help in assessing and selecting celebrities.

\section{Conclusions}

Red Bull is known for its globally standardised provocative style of advertising and does not shy away from controversial topics. With the Napoleon cartoon, a glocal approach is chosen since only some elements of the commercial are standardised (advertising copy, lyrics, slogan), whereas others are not (language, performance, countries screened). Still, the ad contains different meanings and implies different feelings in the consumers when considering their cultural backgrounds. Napoleon, used as a celebrity to relay the meaning of the brand, also evokes different interpretations by the French and British customers. Researchers benefit from the study since it is shown that the same celebrity 
conveying different meanings can still convey the main message. Here, interesting possibilities for glocal advertising arise. As implications for marketing practitioners, care has to be taken when working with celebrities not to overlook the meaning they create. If a celebrity evokes a certain meaning that does not completely match the brand (as in this case Napoleon standing for the old order and despotism), other ingredients of the ad should be selected in order to achieve a fit with the brand. Additionally, practitioners should gain knowledge of all attributes associated with the celebrity and the surroundings (i.e., meanings of Napoleon vs. Kaaris, places where Napoleon is pictured, gestures) with the aim to repeat identical understandings of the commercial globally. The use of the Hofstede dimensions seems to be a valuable tool for predicting how an advertising might be perceived in a given culture, for which the Hofstede indexes are available.

Obviously, this study has certain limitations. The sample size is small and results can only be indicative. In addition, results have neither been differentiated by age groups (knowledge of Napoleon might be higher among elder people), nor by regular consumer/rare consumer. Consumption seems to be influenced by a variety of demographic facts as research has shown (among others age, gender, and income as cited by Capps and Hanselman, 2012). Perceptions can change and influence the interpretation of the commercial, if the respondent is positively/negatively inclined towards the beverage. Future research should include these aspects and research why the cartoon has not been selected to be displayed in all markets served by Red Bull (the German speaking main market of Red Bull has been excluded as well as other European countries).

\section{References}

Agarwal, J., Malhotra, N.K. and Bolton, R.N. (2010) 'A cross-national and cross-cultural approach to global market segmentation: an application using consumers' perceived service quality', Journal of International Marketing, Vol. 18, No. 3, pp.18-40.

Albers-Miller, N.D. and Gelb, B.D. (1996) 'Business advertising appeals as a mirror of cultural dimension: a study of eleven countries', Journal of Advertising, Vol. 25, No. 4, pp.57-70.

Alden, D.L., Steenkamp, J.B. and Batra, R. (1999) 'Brand positioning through advertising in Asia, North America, and Europe: the role of global consumer culture', Journal of Marketing, Vol. 63, No. 1, pp.75-87.

Asprey, R. (2000) The Rise of Napoleon Bonaparte, pp.15-18, Basic Books, New York.

Baabbaki, I. and Malhotra, N. (1995) 'Standardization versus customization in international marketing: an investigation using bridging conjoint analysis', Journal of the Academy of Marketing Science, Vol. 23, No. 3, pp.182-194.

Biswas, A., Olsen, J.E., and Carlet, V. (1992) 'A comparison of print advertisings from the United States and France', Journal of Advertising, Vol. 21, No. 4, pp.73-81.

Biswas, S., Hussain, M. and O'Donnell, K. (2009) 'Celebrity endorsements in advertisements and consumer perceptions: a cross-cultural study', Journal of Global Marketing, Vol. 22, No. 2, pp.121-137.

Boddewyn J., Soehl, R. and Picard, J. (1986) 'Standardization in international marketing? Is Ted Levitt in fact right?', Business Horizons, Vol. 29, No. 6, pp.69-75.

Boyland, E.J., Harrold, J.A., Kirkham, T.C. and Halford, J.C.G. (2012) 'Persuasive techniques used in television advertisements to market foods to UK children', Appetite, Vol. 58, No. 2, pp.658-664.

Bradley, M. (1975) 'Scientific education versus military training: the influence of Napoleon Bonaparte on the Ecole Polytechnique', Annals of Science, Vol. 32, No. 5, pp.415-449. 
Buzzell, R.D. (1968) 'Can you standardize international marketing?', Harvard Business Review, November/December, Vol. 46, No. 6, pp.103-113.

Capps Jr., O. and Hanselman, R.D. (2012) 'A pilot study of the market for energy drinks', Journal of Food Distribution Research, Vol. 43, No. 3, pp.15-29.

Cervellon, M-C. and Dubé, L. (2000) 'Standardisation versus cultural adaptation in food advertising: insights from a two-culture market', International Journal of Advertising, Vol. 19, No. 4, pp.429-447.

Chan, K., Li, L., Diehl, S. and Terlutter, R. (2007) 'Consumer's response to offensive advertising: a cross cultural study’, International Marketing Review, Vol. 24, No. 5, pp.606-628.

Chao, P., Wührer, G. and Werani, T. (2005) 'Celebrity and foreign brand name as moderators of country-of-origin effects', International Journal of Advertising, Vol. 24, No. 2, pp.173-192.

Cho, B., Kwon, U., Gentry, J.W., Jun, S. and Kropp, S. (1999) 'Cultural values reflected in theme and execution: a comparative study of US and Korean television commercials', Journal of Advertising, Vol. 28, No. 4, pp.59-73.

Colvin, M., Heeler, R. and Thorpe, J. (1980) 'Developing international advertising strategy', Journal of Marketing, Vol. 44, No. 4, pp.73-79.

Craig, C. and Douglas, S. (2000) 'Building global brands in the 21st century', Japan and the World Economy, Vol. 12, No. 3, pp.273-283.

Czarnecka, B., Dahl, S. and Eagle, L. (2013) 'Is food advertising culture-bound? Contradictory results from three European countries', Journal of Customer Behaviour, Vol. 12, Nos. 2/3, pp.227-246.

De Pelsmacker, P., Geuens, M. and Van den Bergh, J. (2017) Marketing Communication, Pearson, Harlow, UK.

Domzal, T.J. and Kernan, J. B. (1994) 'Creative features of globally-understood advertisements', Journal of Current Issues and Research in Advertising, Vol. 16, No. 1, pp.29-48.

Duncan, T. and Ramaprasad, J. (1995) 'Standardized multinational advertising: the influencing factors', Journal of Advertising, Vol. 24, No. 3, pp.55-68.

Dunn, W.S. (1976) 'Effect of national identity on multinational promotional strategy in Europe', Journal of Marketing, Vol. 40, No. 4, pp.50-57.

Edson Escalas, J. and Bettman, J.R. (2015) 'Managing brand meaning through celebrity endorsement', in Macinnis, D.J. and Whan Park, C. (Eds.): Brand Meaning Management, Review of Marketing Research, Vol. 12, pp.29-52, Emerald Group Publishing Limited.

Elinder, E. (1965) 'How international can European advertising be?', Journal of Marketing, Vol. 29, No. 2, pp.7-11.

Elliott, R. and Timulak, L (2005) 'Chapter 11: Descriptive and interpretive approaches to qualitative research', A Handbook of Research Methods for Clinical and Health Psychology, pp.147-159, Oxford University Press, Oxford.

Erdogan, B.Z. (1999) 'Celebrity endorsement: a literature review', in Journal of Marketing Management, Vol. 15, No. 4, pp.291-314.

Falk, L.K., Jones, R.W., Foster, D.E. and Rehman, S. (1999) 'Comparative analysis of advertising information in a US and Mexican edition of a men's magazine', International Journal of Commerce and Management, Vol. 9, Nos. 3/4, pp.33-45.

Gau, D. (2007) Erfolgreiche Werbung im interkulturellen Vergleich: Eine Analyse deutsch- und französischsprachiger Werbung, Forum für Fachsprachen-Forschung, Vol. 75, Narr, Tübingen.

Gross, J.P., Brown, H. and Miller, J. (2003) 'Taking liberties: problems of a new order from the french revolution to napoleon', Annales historiques de la Révolution française, No. 334, pp.191-193, Armand Collins, Paris.

Hall, E.T. (1976) Beyond Culture, Anchor Books, Doubleday, Garden City, New York. 
He, J. and Wang, C.L. (2017) 'How global brands incorporating local cultural elements increase consumer purchase likelihood: an empirical study in China', International Marketing Review, Vol. 34, No. 4, pp.463-479.

Heald, T (2001) A Peerage For Trade: A History Of The Royal Warrant, Royal Warrant Holders Association in association with Sinclair-Stevenson, London.

Hebden, L., King, L., Kelly, B., Chapman, K. and Innes-Hughes, C. (2011) 'A menagerie of promotional characters, promoting food to children through food packaging', in Journal of Nutrition Education and Behaviour, Vol. 43, No. 5, pp.349-355.

Hofstede, G. (1980) Culture's Consequences: International Differences in Work-Related Values, Sage Publications, Beverly Hills, California.

Hofstede, G. (2001) Culture's consequences: Comparing Values, Behaviors, Institutions, and Organizations Across Nations, 2nd ed., Sage Publications, Thousand Oaks CA.

Hofstede, G.J. and Minkov, M. (2010) Cultures and Organizations: Software of the Mind, revised and expanded 3rd ed., McGraw-Hill, New York.

Hovland, C.I., Irving, L.J. and Kelly, H.H. (1953) Communication and Persuasion: Psychological Studies of Opinion Change, Yale University Press, New Haven.

Hussy, W., Schreier, M. and Echterhoff, G. (2013) 'Forschungsmethoden in psychologie und sozialwissenschaften für bachelor', Qualitatative Forschungsmethoden, pp.189-221, Springer Verlag, Berlin/Heidelberg.

Javalgi, R., Culter, B. and Malhotra, N. (1995) 'Print advertising at the component level: a cross-cultural comparison of the United States and Japan', Journal of Business Research, Vol. 34, No. 2, pp.117-124.

Ji, M.F. and McNeil J.U. (2001) 'How Chinese children's commercials differ from those of the United States: a content analysis', Journal of Advertising, Vol. 30, No.3, pp.79-92.

Jiang, J. and Wei, R. (2012) 'Influences of culture and market convergence on the international advertising strategies of multinational corporations in North America, Europe and Asia', International Marketing Review, Vol. 29, No. 6, pp.597-622.

Jones, M.L. and Hofstede, G. (2007) 'Hofstede - culturally questionable?', in the Proceedings of the Oxford Business and Economics Conference, Oxford, 24-26 June 2007.

Kanso, A. (1992) 'International advertising strategies: global commitment to local vision', Journal of Advertising Research, Vol. 32, No. 1, pp.10-14.

Karande, K., Almurshidee, K.A. and Al-Olayan, F. (2006) 'Advertising standardisation in culturally similar markets: can we standardise all components?', International Journal of Advertising, Vol. 25, No. 4, pp.489-512.

La Salle, A. (1788) La Balance Naturelle, Ou Essai Sur Une Loi Universelle Appliquée Aux Sciences, Arts Et Métiers, Et Aux Moindres Détails De La Vie Commune, London.

Levitt, T. (1983) 'The globalization of markets', Harvard Business Review, Vol. 61, No. 3, pp.92-102.

Light, L. (2013) 'How organisations manage global brands in an increasingly local world', Journal of Brand Strategy, Vol. 2, No. 3, pp.228-235.

Lin, C.A. (1993) 'Cultural differences in message strategies: a comparison between American and Japanese TV commercials', Journal of Advertising Research, Vol. 33, No. 3, pp.40-48.

Lyons, M. (1994) Napoleon Bonaparte and the legacy of the French revolution, Vol. 1, Macmillan, London, England.

Marimoto, M. and Chang, S. (2009) 'Western and Asian models in Japanese fashion magazine ads: the relationship with brand origins and international versus domestic magazines', Journal of International Consumer Marketing, Vol. 21, No. 3, pp.173-187.

McCracken, G. (1989) 'Who is the celebrity endorser? Cultural foundations of the endorsement process', Journal of Consumer Research, Vol. 16, No. 3, pp.310-321.

McGuire, W.J. (1985) 'Attitudes and attitude change', in Gardner, L and Aronson, E. (Eds.): Handbook in Social Psychology, Random House, London. 
Mooij, M. de (2010) 'Mental processes across cultures: implications for branding and communication', Communicative Business. Italian Research Review on Business Communication, Vol. 1, No. 1, pp.27-49.

N.N. (2012) 'Red Bull: a trailblazer in marketing strategy', Red Bull: A Trailblazer in Marketing Strategy, Marketline Case Study, Ref. ML00007-12.

Nanda, A.K. and Khandelwal, P. (2017) 'Celebrity endorsement: a review and research agenda', in CLEAR International Journal of Research in Commerce and Management, Vol. 8, No. 7, pp.49-54.

Nicholson, R.R. and Khan, Z. (2017) 'Standardization versus adaptation of global marketing strategies in emerging market cross-border acquisitions', International Marketing Review, Vol. 34, No. 1, pp.138-158.

Ogilvy, D. and Raphaelson, J. (1982) 'Research on advertising techniques that work--and don't work', in Harvard Business Review, Vol. 60, No. 4, p.14.

Okazaki, S. and Rivas, J.A. (2002) 'A content analysis of multinationals' web communication strategies: cross-cultural research framework and pre-testing', Internet Research, Vol. 12, No. 5, pp.380-390.

Oosthuizen, T. (2004) 'In marketing across cultures: are you enlightening the world or are you speaking in tongues?', Design Issues, Vol. 20, No. 2, pp.61-72.

Prentice, C. and Zhang, L. (2017) 'Celebrity endorsement and stock market return', Marketing Intelligence and Planning, Vol. 35, No. 4, pp.529-543.

Prévot, C. (2011) 'Napoléon en exil à Sainte-Hélène. 1re partie: le temps de l'exil', Napoleonica La Revue, Vol. 11, No. 2, pp.32-37.

Quelch, J. (1999) 'Global brands: taking stock', Business Strategy Review, Vol. 10, No.1, pp.1-14.

Rennie, D., Phillips, J. and Quartaro, G. (1988) 'Grounded theory: a promising approach to conceptualization in psychology?', Canadian Psychology/Psychologie Canadienne, Vol 29, No. 2, pp.139-150.

Ricks, D.A., Arpan, J.S. and Fu, M.Y. (1974) 'Pitfalls in advertising overseas', Journal of Advertising Research, Vol. 14, No. 6, pp.47-51.

Sandler, D.M. and Shani, D. (1992) 'Brand globally but advertise locally? An empirical investigation', International Marketing Review, Vol. 9, No. 4, pp.18-29.

Scott, L.M. (1991) 'The troupe: celebrities as dramatis personae in advertisements', Advances in Consumer Research, Vol. 18, No. 1, pp.355-363.

Scully, R. (2011) 'The cartoon emperor: the impact of Louis Napoleon Bonaparte on European comic art, 1848-1870', European Comic Art, Vol. 4, No. 2, pp.147-180.

Solberg, C.A. (2002) 'The perennial issue of adaptation or standardization of international marketing communication: organizational contingencies and performance', Journal of International Marketing, Vol. 10, No. 3, pp.1-21.

Sorensen, R.Z. and Wiechmann, U.E. (1975) 'How multinationals view marketing standardization', Harvard Business Review, Vol. 53, No. 3, pp.38-54.

Strebinger, A., Guo, X., Klauser, F. and Grant-Hay, P. (2018) 'Is multi-ethnic advertising a globally viable strategy for a Western luxury car brand? A mixed method cross-cultural study', Journal of Business Research, Vol. 82, No. 1, pp.409-416.

Taylor, C.R., Miracle, G.E. and Wilson, R.D. (1997) 'The impact of information level on the effectiveness of US and Korean television commercials', Journal of Advertising, Vol. 26, No. 1, pp.1-18.

Theodosiou, M. and Katsikeas, C. (2001) 'Factors influencing the degree of international pricing strategy standardization of multinational corporations', Journal of International Marketing, Vol. 9, No. 3, pp.1-18.

Torres Moraga, E. and Muñoz Navarro, C. (2006) 'Estrategias de posicionamiento basadas en la cultura del consumidor: un análisis de la publicidad en televisión', Estudios Gerenciales, Vol. 22, No. 100, pp.71-81. 
Um, N-H. (2013) 'The role of culture in creative execution in celebrity endorsement: the cross-cultural study', Journal of Global Marketing, Vol. 26, No. 3, pp.155-172.

Wadia, M.S. (1965) 'The concept of culture', Journal of Retailing, Vol. 41, No. 1, p.21.

Wang, S.W. and Ngamsiriudom, W. (2015) 'Celebrity livery featured aircraft, the Moneki Neko (fortune cat) of airlines', Journal of Air Transport Management, Vol. 42, No. January, pp.110-117.

Whitelock, J. and Rey, J-C. (1998) 'Cross cultural advertising in Europe: an empirical survey of television advertising in France and the UK', International Marketing Review, Vol. 15, No. 4, pp.257-276.

Wiles, J.A., Wiles, C.R. and Tjernlund, A. (1995) 'A comparison of gender role portrayals in magazine advertisement: the Netherlands, Sweden and the USA', European Journal of Marketing, Vol. 29, No. 11, pp.35-49.

Zandpour, F., Campos, V., Catalano, J., Chang, C., Young, D.C., Hoobyar, R., Shu-Fang, J., Man-Chi, L., Madrid, S., Scheideler, H. and Osborn, S.T. (1994) 'Global reach and local touch: achieving cultural fitness in TV advertising', Journal of Advertising Research, Vol. 34 No. 5, pp.35-63.

Zou, S. and Cavusgil, S. (2002) 'The GMS: a broad conceptualization of global marketing strategy and its effect on firm performance', Journal of Marketing, Vol. 66, No. 4, pp.40-56.

\section{Appendix}

Table A1 Interview guideline

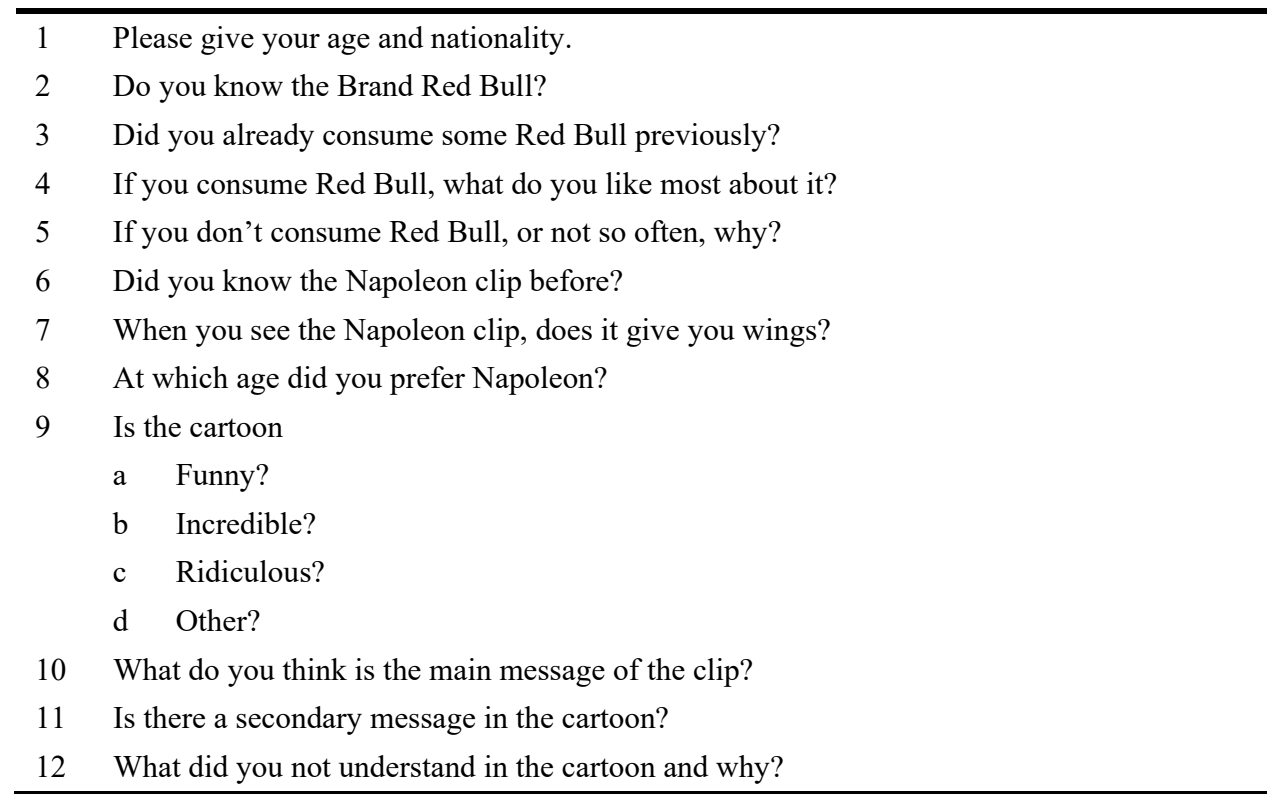


Table A1 Interview guideline (continued)

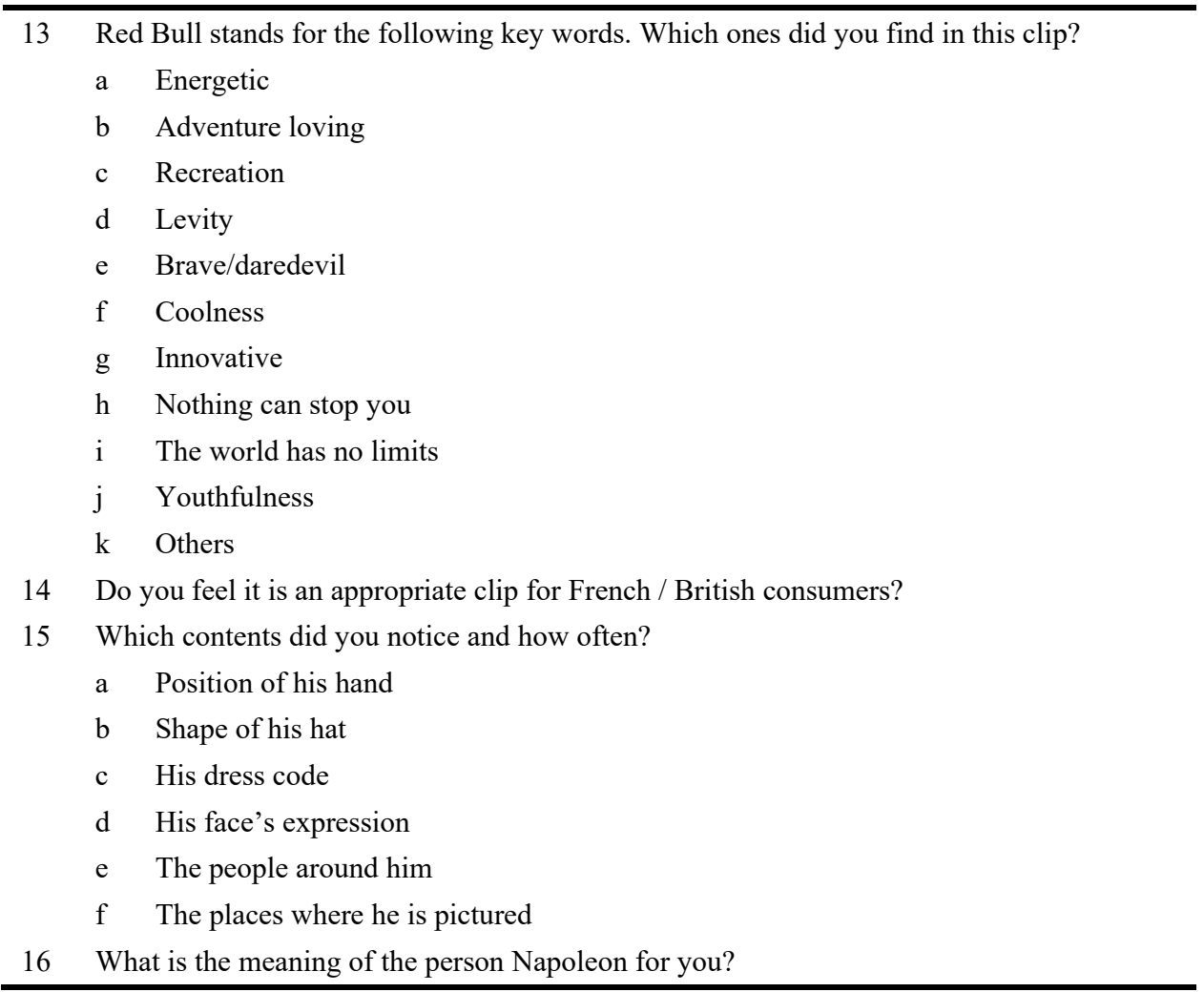

